\title{
REPORT OF PROGRESS
}

The following data and information are organized into three sections, a description of project personnel, a summary of administrative and technical ties with other Deep Subsurface project elements and a summary of technical progress within the University of Arizona DOE unit.

\section{Summary of Personnel}

The following individuals are involved on a full- or part-time basis in this research at the University of Arizona.

Roger Bales, Hydrology Department. Water Chemist with experience in microbial transport through porous media, transport/surface chemical relationships and modelling of pollutant or colloid transport in groundwater. Projest principal investigator.

Charles Gerba, Department of Soil and Water Science. Microbiologist with immense experience in the fields of pathogen/virus transport and inactivation in the subsurface environment. Chuck is among the world leaders in the area of virus transport including surface-chemical properties that effect virus mobility or stickiness in porous media. He is a co-principal investigator.

Robert Arnold, Department of Civil Engineering and Engineering Mechanics. Environmental Engineer with an interest in microbiology, including microbial transport through porous media. Project co-principal investigator.

Bruce Logan, Department of Civil Engineering and Engineering Mechanics. Chemical Engineer with interest and experience in the transport of colloids, including microorganisms, through porous media. Bruce has developed new screening procedures for convenient measurement of bacterial stickiness under laboratory conditions and has made a number of particle-media collision frequency models on this project accessible to the project team on a PC computer.

Otto Albinger, Post-doctoral researcher within the Department of Soil and Water Science. Otto is a graduate of University of Vienna. His primary responsibilities on the project include developmentapplication of methods for screening deep subsurface isolates for mobility/stickiness in porous media. He will also direct/participate lab and intermediate-scale experiments designed to test hypotheses deveioped on the basis of bench-scale (screening) results. Otto is the lone full-time enployee on this project and will be instrumental to its progress and success.

Doug McCaulou, Masters student in the Department of Hydrology and Water Resources. Doug is completely funded by the Deparment of Energy through an Environmental Restoration/Waste Management fellowship. His responsibilities

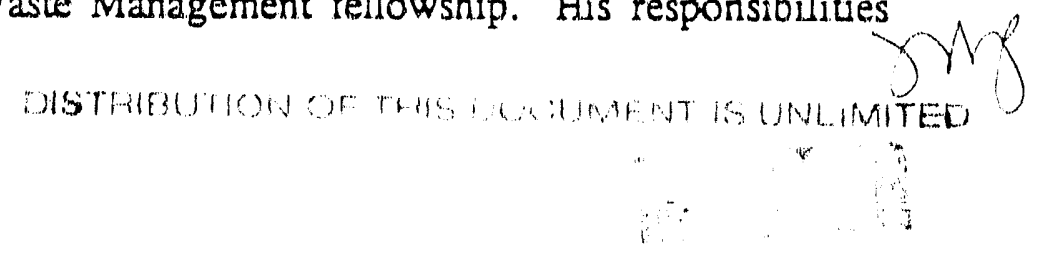




\section{DISCLAIMER}

This report was prebared as an account of work sponsored by an agency of the United States Government. Neither the United States Covernment nor any agency thereof, nor any of their employees, makes any warranty, express or implied, or assumes any legal liability or responsibility for the accuracy. completeness. or usefulness of any information, apparatus, product, or process disclosed, or represents that its use would not infringe privately owned rights. Refer. ence herein to any specific commercial product, process, or service by trade name, trademark, manufacturer, or otherwise does not necessarily constitute or imply its endorsement, resommendation, or favoring by the United States Government or any agency thereof The views and opinions of authors expressed herein do not necessarily state or refiect those of the United States Government or any agency thereol. 
on the project include design and eventual operation of intermediate-scale soil columns for saturated and unsaturated flow, microbial transport experiments. These will extend the screening experiments and will be premised in part on the hypotheses that were formulated in bench-scale work. As above, microbes will be obtained from deep subsurface collections, primarily those obtained from the Hanford site. Column materials will be native to the Ranford site.

Shimin Li, Ph.D. student in the Department of Hydrology and Water Resources. Shimin is involved in model development and application to microbial transport through porous media.

Ernest Hardin, Ph.D. student in the Department of Hydrology and Water Resources. This student comes at no cost to the project. He will participate in a Battelle project (GEMHEXX) at the Pacific Northwest Laboratory this summer in which working hypotheses regarding the relationships between microbial abundance and physical/chemical subsurface conditions will be tested. The project may also solidify scientific relations between the University and PNL and provide the basis of a potential joint venture into the projected DOE microbial origins program.

In Fall 1992, a second graduate student will be added to the project. She/he will be responsible for the conduct of microbial transport experiments in intermediate or field-scale lysimeters.

\section{Administrative/scientific relationships with other Deep Subsurface program elements}

The following activities contribute to our present scientific relationship with and dependence upon other Department of Energy, Deep Subsurface Program elements.

1. We have selected, and will continue to screen, organisms from the Savannah River and Hanford deep subsurface sediments. The immense size of these collections makes exhaustive investigation infeasible; we are selecting potentially interesting organisms from a wide variety of genera, primarily on the basis of taxonomy, size, colony color (for ease in identification in mixed-rulture experiments), motility, etc. Fortunately, David Balkwill has summarized these characteristics for a great many microorganisms in his Savannah River collection, making it possible to select organisms for screening studies by sorting on the traits of interest. David has already supplied a comprehensive data file for the Savannah River collection and has promised to provide a similar description of the Hanford isolates. He provided Savannah River organisms selected for our initial screening studies. See below.

2. Intermediate-scale and bench-scale (mini-columns) screening tests are being initiated using soils provided by Battelle personnel in Hanford. Materials for the initial characterization of soils and shake-down experiments involving intermediate-scale columns were obtained by our investigators following consultation with Battelle scientists, Phil Long, Bruce Bjornstad and Shirley Rawson. A location was chosen that will permit us to obtain additional materials with 
relative ease, although we will be entirely dependent on the Battelle people to carry out that functirn. Battelle also provided brief analyses of soil and local groundwater characteristics to facilitate development of an appropriate liquid medium for transport experiments.

3. Bob Amold was a participant in the planning meeting of Ellen Murphy's Coupled Processes subgroup. The interest of that group in Fe(III)-reducing microorganisms and their ecological function in the microbial community creates avenues for scientific interactions with the Arizona investigators outside the area of microbial transport. It is true, however, that the Battelle's group of environmental microbiologists at PNL (Fredrickson, Brockman, Yorby) is entirely adequate in this area. There have already been several opportunities for direct: communication between the PNL microbiological group and the co-investigators of this project. We will benefit greatly from continued association, due to both their general competence and their experience with techniques for culturing microorganisms from the deep subsurface. Other DOE investigators with whom we have communicated directly regarding goals and progress in DOE research include John McCarthy, Jim Szecsody, Brian Wood, Aaron Mills, Janet Herman, John Zachara, Harvey Bolton and Liyuan Liang.

4. We have benefited from direct discussions with Therese Olson of California Irvine regarding the treatment of sand or glass beads for inclusion in columns containing porous media. In particular, Teuri has traced a lack of experimental reproducibility in colloid transport experiments directly to media preparation and, as a consequence, she sorts media by size using a sedimentation technique rather than seiving.

5. Finally, we will continue to promote interaction with Battelle/PNL environmental and hydrology staff in the future. This relationship is especially promising due to the University of Arizona backgrounds of key Battelle personnel (Murphy, Szecsody) and our similarities of purpose. It may be possible to generate a joint "microbial origins" proposal with elements to te pursued at both the University of Arizona and the Pacific Northwest Iaboratory.

\section{Technical Progress}

1. Screening experimtents. Efforts to date were undertaken to (i) develop a convenient screening procedure with which to measure bacterial stickiness and (ii) apply that procedure to assess the stickiness of deep subsurface isolates.

Logan et al. (submitted) both developed and evaluated a rapid screening procedure with which to measure bacterial stickiness in commercially manufactured filter materials. Although this has proven to be a useful tool within this context as well, the procedure suffered from several important limitations. In order to obtain an absolute measure of collision efficiency $(\alpha)$, it was necessary to make certain simplifying assumptions about filter geometries. If these are not valid, the procedure provides only a relative measure of $\alpha$. It was not possible to obtain or develop a detailed characterization of the surface properties of filter materials, rendering suspect the obligatory extrapolation of filter screening results to aquifer materials. 
Finally, the contribution of straining to bacterial removal in the filters was difficult to estimate or mathematically model, since average pore sizes are larger than bacterial diameters. As a consequence, bacterial straining, which was independent of the normal collision mechanisms-gravitational settling, diffusional transport and interception- may have produced low-level attenuation and an apparent stickiness that make it impossible to measure very low $\alpha$ values using the filter screening procedure. For these reasons, a second screening device was adopted for the DOE work. Transport experiments were conducted in 1-cm diameter glass columns containing $9.0 \mathrm{~mm}$ of $40 \mu \mathrm{m}$ borosilicate beads. The column apparatus is further described in Figure 1. Media size was considered optimal from the standpoints of (i) minimization of bacterial straining- pore sizes were considerably greater than bacterial dimensions and (ii) minimization of column length- see below.

The validity of the glass bead column as a screening device was first tested in parallel with glass fibre (GFC) filters using a bacterial species, Pseudomonas fluorescens P17, that had been previousiy tested and a range of operational conditions in which the glass fibre filters provided a sensitive measure of bacterial adhesion or stickiness. P. fluorescens P17 was grown in batch culture, and samples were periodically withdrawn for the measurement of stickiness via each technique. Sample points and bacterial growth characteristics are illustrated in Figure 2. A description of the $\mathrm{P}$. fluorescens $\mathrm{P} 17$ growth medium is provided in Table 1 . In each sample, bacteria were removed and diluted 1:150 in buffer solution A (Table 1). Resuspended cells served as influent to both columns and filters for the measurement of bacterial stickiness. Influent and effluent cell numbers were established using acridine orange direct counts, and retention lata were converted to estimates of bacterial stickiness using filter/column characteristics and previously established models for calculating collision frequencies. See below.

Results are summarized in Figure 3. It is apparent that filter and column reactors have retention characteristics that are well correlated under the range of conditions employed in these tests. On this basis, and because of the aforementioned shortcomings of the filter procedure, a standard column was adopted as the method of choice for measuring, or at least comparing, the stickiness of deep subsurface isolates in subsequent tests.

The initial tests involving deep-surface isolates were conducted using five species of significantly different character from the Savannah River archives of David Balkwill. Reievant bacterial properties are summarized in Table 2. Unfortunately, it was impossible to anticipate growth characteristics from the descriptive data associated with the deep-subsurface collections, and two of the five species requested proved to be extremely slow growers (Figure 4) and were temporarily set aside. Two others aggregated or grew in clusters and were not appropriate candidates for testing using screening procedures based on passage through porous media with modest pore sizes. Agitation using a. Vortex mixer failed to disperse these cells. The lone remaining species, identified only as A0500, was used exclusively in the initial tests.

As in the prescreening tests involving $\mathrm{P}$. fluorescens, multiple bacterial samples were taken at various points representing late logarithmic and stationary growth phases. The $40-\mu \mathrm{m}$ 
borosilicate beads were retained in the column apparatus by a $35 \mu \mathrm{m}$ fritted plate at the column base. To estimate bacterial retention by the frit and glass walls, a media-free (frit-only) column control was used at all sampling points. Removal of cells by the fritted retainer was minimal, and in no case did the borosilicate medium and frit retain significantly more cells than the frit alone. It is concluded that species A0500 was not retained in the column to a measurable degree. Comparison with data generated using the same apparatus and P. fluorescens P17 suggests that the Savannah River microorganism is considerably less sticky and could have favorable transport characteristics in porous media.

Because bacterial retention was below the limits of detection in this case, it is not possible to obtain an estimate for the sticking coefficient. It is possible, however, to obtain an upper limit using established theory (see below) and an estimate of the sensitivity of the column procedure. It is likely, for example, that we are able to measure reliably a 10 percent reduction in cell number due to retention in the borosilicate medium (as opposed to the frit). Application of the Yao/O'Melia model (see below) using the column and medium geometries and 5 percent retention yields an expected $\alpha$ value of $5.0 \times 10^{-2}$. The actual value may be significantly lower, but a deeper bed of the borosilicate beads will be required to obtain a realistic estimate. These and screening experiments involving other deep subsurface organisms are on our immediate agenda.

To assure ourselves that the transport characteristics of Savannah River strain A0500 were not an experimental artifact, generated via our newly established short-column screening procedure, we retested the strain using the commercial-filter procedure developed previously. Cells were grown into late logarithmic growth phase in PTYG, diluted in MOPS buffer/nutrient solution without glucose to $10^{6} \mathrm{cells} / \mathrm{ml}$ and passed through a GF/D (Whatman) glass, microfibre filter. Cells that passed through the filter were stained using AODC, collected on a $0.2 \mu \mathrm{m}$ Poretics black filter and counted using epifluorescence microscopy. Fraction retained was estimated from numbers in filtered and unfiltered samples. Results, summarized in Table 3, indicate that less than 10 percent of the organisms applied to the GF/D filter were retained. This fraction could have been removed via straining, as opposed to other mechanisms, and suggests that the stickiness of the microorganism was in fact very low. Retentions of other species used to develop the filtration/screening test were much higher.

2. Design and manufacture of intermediate-scale columns. The results of screening experiments will eventually be used to test hypotheses relative to bacterial transport through porous media that are characteristic of the lacustrine sediments in the Franford area. We have completed construction of a single 36-inch column that will be used in this manner. Des:-gn details are provided in Figure 5. The column can be used for saturated or unsaturated flow experiments. T'ensiometers located at intervals along the column length, in conjunction with an adequate moisture retention curve, permit continuous monitoring of column moisture content during unsaturated-flow experiments. There are also liquid withdrawal points that are firted with sintered, stainless steel cups designed to permit sampling for liquid and microorganisms without exceeding the air entry value of the material. Liquid application rates can be monitored continuously. Accumulation of liquid in the bottom of the column is avoided by application of 
3 slight vacuum (several inches of $\mathrm{H}_{2} \mathrm{O}$ ) at the base of the column. The chemical composition of the liquid feed will be similar to local (Hanford) groundwater quality in terms of major cations and ionic strength. Columns two and three, identical in design, are under construction. Parallel operation of columns will support the systematic investigation of independent variables that are potentially important determinants of bacterial transport characteristics.

3. Modeling. The basic modeling approach builds on that described in our previous work on virus transport, with further detailed description of chemical interactions between bacteria and soil. The basic transport equations for one-dimensional experiments are:

$$
\begin{gathered}
\theta \frac{\partial c}{\partial t}+\rho_{b} \frac{\partial s}{\partial t}=\theta D \frac{\partial^{2} C}{\partial x^{2}}-\theta u \frac{\partial c}{\partial x} \\
\rho_{b} \frac{\partial s}{\partial t}=\theta k_{1} C-\rho_{b} k_{2} S
\end{gathered}
$$

where $C$ and $S$ are the aqueous and attached bacterial concentrations, $\theta$ is porosity, $\rho_{b}$ is bulk density, $D$ is the dispersion coefficient, $u$ is velocity, $k_{1}$ is the rate coefficient for bacterial removal and $k_{2}$ is the rate coefficient for bacterial addition to the water. In our experiments, the dominant removal process is attachment to sand grains and the dominant addition process is detachment from sand grains.

We have generally run experiments long enough to achieve steady state, permitting a simplified form of equations (1) and (2) and facilitating interpretation of $k_{1}$. The full, unsteady equation is used for estimating $\mathrm{k}_{2}$.

Several useful models are available for interpreting $k_{1}$ and predicting collision frequencies $(\eta)$ between the porous media collector (borosilicate glass beads or Hanford aquifer material) and colloidal bacteria, as driven by sedimentation, Brownian motion and particle interception. In terms of "irreversible" attachment, as described in colloid-filtration theory,

$$
k_{1}=\frac{1-\theta}{d} \eta \alpha C
$$

where $d$ is collection diameter, $\eta$ is the bacteria-sand collision frequency and $\alpha$ is the sticking efficiency.

Model formulations, summarized subsequently, have been programmed for use by the project team. The stickiness coefficient, $\alpha$, is equal to the fraction of particle/collector collisions 
that result in removal of colloidal particles from the liquid phase.

The five filtration models available for local use are based on the same steady state solution of the reduction in particle concentration after flow though a filter of length $L$, calculated as:

$$
\frac{C_{e}}{C_{0}}=e^{-\xi \alpha \phi \eta \frac{z}{d_{g}}}
$$

where $C_{0}$ and $C_{0}$ are the aquasol concentrations entering and leaving a filter, $\xi$ is a geometric factor equal to $3 / 2$ for spherical and $4 / \pi$ for cylindrical collectors of diameter $d_{e}, \alpha$ the sticking coefficient of the particle with the collector, $\phi=(1-p)$ the solid fraction $(p$ is the filter-bed porosity), and $\eta$ the single collector collision efficiency, which is a function of the filter geometry and fluid hydrodynamics. The single-collector efficiency is the sum of collector efficiencies for transport of a particle of size $d_{\mathrm{D}}$ to the collector by diffusion $\left(\eta_{\mathrm{D}}\right)$, interception $\left(\eta_{1}\right)$, gravity $\left(\eta_{\mathrm{a}}\right)$, and impaction $\left(\eta_{w_{2}}\right)$. Collector efficiencies are dimensionless, and are developed from correlations involving the following dimensionless numbers:

$$
\begin{aligned}
P e & =\frac{U_{o} d_{c}}{D} \\
R & =\frac{d_{p}}{d_{c}} \\
G & =\frac{U_{p}}{U_{o}} \\
S t k & =\frac{U_{p} U_{o}}{g d_{c}} \\
F u & =1+\frac{d_{p}}{d_{h}} \\
R_{c} & =\frac{E}{\mu d_{p}^{2} U_{o}}
\end{aligned}
$$


where $d_{h}$ is the average pore diameter of the filter, $U_{0}$ and $U_{p}$ the filter superficial velocity and particle settling velocities, $D$ the particle diffusivity, $g$ the gravitational constant, $\mu$ the fluid dynamic viscosity, E a constant equal to $10^{-13} \mathrm{erg}, \mathrm{R}$ and $\mathrm{G}$ the interception and gravitational numbers, $R_{v}$ an interception co-factor, and Pe, Fu and Stk are the Peclet, Fuchs and Stokes numbers. The particle settling velocity is obtained from Stokes Law, or:

$$
U_{p}=\frac{g\left(\rho_{p}-\rho_{f}\right) d_{p}^{2}}{18 \vee \rho_{f}}
$$

where $\nu$ is the kinematic fluid viscosity, $\rho_{p}$ and $\rho_{\mathrm{f}}$ the particle and fluid densities. The particle diffusivity is obtaines from the Stokes-Einstein equation as:

$$
D=\frac{k T}{3 \pi d_{p}}
$$

where $\mathrm{k}$ is Boltzman's constant $\left(1.38 \times 10^{-23} \mathrm{~J}^{\circ} \mathrm{K}^{-1}\right)$ and $\mathrm{T}$ is the absolute temperature. The equations proposed by Yao et al. (1971), Hinds (1983), Rubow and Liu (1986), Tien and Payatakes (1976), and Fuchs (1964) to calculate particle removal in filters are presented below.

Yao Model: Filtration equations describing deep-bed filtration of aquasols were originally proposed by Yao et al. (1971). Single collector efficiencies for the Yao model are based on spherical collectors, and are:

$$
\begin{aligned}
& \eta_{D}=4 \dot{P e^{-\frac{2}{3}}} . \\
& \eta_{I}=\frac{3}{2} R^{2} \\
& \eta_{G}=G
\end{aligned}
$$

This model was shown to provide reasonable agreement with data on the removal of latex beads in packed-bed columns. However, when packing material was covered with a coagulant aid, sticking coefficients greater than unity were indicated.

Hinds Model: There has been extensive research on aerosol rerioval by fibrous mats composed of cylindrical particles. Hinds (1983) suggested the use of the following relationships:

$$
\eta_{D}=2 P e^{-\frac{2}{3}}
$$

Correction factors for slippage presented in the original work on aerosols are assumed to be negligible for aquasols, since the mean free path of water molecules relative to fiber diameters 


$$
\begin{gathered}
\eta_{I}=\frac{1}{2 K \mu}\left[2(1+R) \ln (1+R)-(1+R)+\left(\frac{1}{1+R}\right)\right] \\
\eta_{G}=G(1+R)
\end{gathered}
$$

is much smaller for liquids than for gases (Fuchs 1964). The Kuwabara number, Ku, is calculated from:

$$
K u=-\frac{\ln \phi}{2}-\frac{3}{4}+\phi-\frac{\phi^{2}}{4}
$$

Hinds also incorporated a term for particle impaction to account for particle removal due to departures from curved streamlines due to particle inertia. The single collector efficiency for removal by impaction, $\eta_{M}$, is:

$$
\eta_{\mu}=\frac{J S t k}{2 K u^{2}}
$$

where $J$ is empirically determined from:

$$
\begin{aligned}
& J(R \geq 0.4)=2 \\
& J(R<0.4)=\left(29.6-28 \phi^{0.62}\right) R^{2}-27.5 R^{2.8}
\end{aligned}
$$

Rubow and Liu Model: Under experimental conditions established by Rubow and Liu (1986) for aerosol removal by laboratory filters, only particle capture by diffusion and interception were important. Single fiber efficiencies for the Rubow and Liu model are:

$$
\begin{gathered}
\eta_{D}=2.86 p^{1 / 3} K^{-1 / 3} \mathrm{Pe}^{-2 / 3} \\
\eta_{I}=\frac{p R^{2}}{K u(1+R)}
\end{gathered}
$$

It is also assumed for this model that slip factors introduced into the original formulations for aerosols are insignificant for aquasols (Fuchs 1964). Rubow and Liu also used a geometrical factor of $\xi=4 \zeta / \pi$, where $\zeta$ is an empirical inhomogeneity factor calculated to be 1.67 for polyester filter fibers. The inhomogeneity factor was introduced to account for random fiber orientation and non-uniform separation distances between filter collectors.

Tien and Payatakes Model: This model was developed for deep bed filtration of colloidal particles in dilute liquid suspensions (1976), and was shown to provide reasonable 
agreement with data from Yao et al. (1971). The following correlations were derived governing collision frequencies:

$$
\begin{gathered}
\eta_{D}=4 A_{s}^{1 / 3} P e^{-2 / 3} \\
\eta_{I}=0.56 A_{s} R_{c}^{1 / 3} R^{15 / 8} \\
\eta_{G}=2.4 \times 10^{-3} A_{s} G^{1.2} R^{-0.4}
\end{gathered}
$$

where

$$
A_{s}=\frac{1-P^{5}}{1-\frac{3}{2} P+\frac{3}{2} P^{5}-P^{6}}
$$

and where $P=(1-p)^{1 / 3}$.

Fuchs Model: For dense filters, Fuchs (1964) developed the following equations assuming flow through capillary pores:

$$
\begin{gathered}
\eta_{D}=\frac{\pi 2^{\frac{2}{3}} F u^{\frac{7}{3}}}{3^{\frac{1}{6}} \phi P e^{\frac{2}{3}}(1-F u)^{\frac{2}{3}}} \\
\eta_{I}=\frac{\pi 3^{\frac{1}{2}} R^{2} F u^{3}}{4 \phi(1-F u)^{2}} \\
\eta_{G}=\frac{\pi G F u^{2}}{2 \phi 3^{\frac{1}{2}}} \\
\eta_{M}=\frac{\pi S t k F u^{2}}{2 \phi 3^{\frac{1}{2}}(1-F u)^{2}}
\end{gathered}
$$


Part of our current effort focuses on establishing consistency between model and observation for $\alpha$. We have written a convenient set of algorithms to estimate the dependence of $\alpha$ on $\mathrm{pH}$, ionic strength and media hydrophobicity using equations and numerical procedures described in the literature. Model testing is in progress. 
TABLE 1. Conposition of Bacterial Growth Media Used in Screening Equipment

\begin{tabular}{|c|c|}
\hline \multicolumn{2}{|l|}{ A. PTYG MEDTUM } \\
\hline DifCO PEPTONE & $5.0 \mathrm{~g}$ \\
\hline DifCo TRYPTONE & $5.0 \mathrm{~g}$ \\
\hline Difco YEAST EXTRACT & $10.0 \mathrm{~g}$ \\
\hline GLUCOSE & $10.0 \mathrm{~g}$ \\
\hline $\mathrm{MgSO}_{4} \cdot 7 \mathrm{H}_{2} \mathrm{O}$ & $0.6 \mathrm{~g}$ \\
\hline $\mathrm{CaCl}_{2} \cdot 2 \mathrm{H}_{2} \mathrm{O}$ & $0.07 \mathrm{~g}$ \\
\hline AGAR (optional) & $1.0 \mathrm{~g}$ \\
\hline Distilled WATER & 1.0 iiter \\
\hline \multicolumn{2}{|l|}{ B. $5 \%$ PTYY G MEDIUM } \\
\hline DifCo PEPTONEE & $0.25 \mathrm{~g}$ \\
\hline DifCo TRYPTONE & $0.25 \mathrm{~g}$ \\
\hline Difco YEAST EXTRACT & $0.5 \mathrm{~g}$ \\
\hline GLUCOSE & $0.5 \mathrm{~g}$ \\
\hline $\mathrm{MgSO}_{4} \cdot \mathrm{TH}_{2} \mathrm{O}$ & $0.07 \mathrm{~g}$ \\
\hline $\mathrm{CaCl}_{2} \cdot 2 \mathrm{O}_{2} \mathrm{O}$ & $0.07 \mathrm{~g}$ \\
\hline AGAR (optional) & $15.0 \mathrm{~g}$ \\
\hline Distilled WATER & 1.0 liter \\
\hline \multicolumn{2}{|c|}{ MOPS-BUFFER/NUTRIENTS } \\
\hline MOPS BUFFER (Na salt) & $4.626 \mathrm{~g}$ \\
\hline $\mathrm{CaCl}_{2} \cdot 2 \mathrm{H}_{2} \mathrm{O}$ & $0.0885 \mathrm{~g}$ \\
\hline $\mathrm{MgSO}_{4} \cdot \mathrm{TH}_{2} \mathrm{O}$ & $0.05 \mathrm{~g}$ \\
\hline $\mathrm{NH}_{4} \mathrm{Cl}$ & $1.00 \mathrm{~g}$ \\
\hline $\mathrm{FeCl}_{3}$ & $0.04 \mathrm{mg}$ \\
\hline $\mathrm{K}_{2} \mathrm{HPO}_{4}$ & $0.0174 \mathrm{~g}$ \\
\hline GLUCOSE & $0.250 \mathrm{~g}$ \\
\hline Distilled WATER & 1.0 liter \\
\hline $\mathrm{pH}: 7.2( \pm 0.1)$ & \\
\hline
\end{tabular}




\begin{tabular}{|l|c|}
\hline BACTERIAL STRAIN & GROWTH MEDIUM \\
\hline A0500 & PTYG \\
\hline A0368 & PTYG \\
\hline B0458 & PTYG \\
\hline B0119 & PTYG \\
\hline A1277 & 5\% PTYG \\
\hline P. fluorescens P17 & MOPS BUFFER/NUTRIENTS \\
\hline
\end{tabular}


TABLE 2. Properties of DOE Bacteria Obtained from the Sarannah River, Deep-Subsurface Collection

\begin{tabular}{|l|l|l|l|l|l|l|l|l|l|}
\hline No. & gr & Dm & GF & ME & T & Sp & Si & Col & Sh \\
\hline B0119 & - & 118 & EI & PY & 23 & NO & S & Y/L & C \\
\hline B0458 & - & 180 & PD & PY & 23 & NO & L & Y & C \\
\hline A1277 & + & 203 & MD & P1 & 23 & NO & S & P/L & C \\
\hline A0368 & + & 276 & MD & PY & 23 & NO & L & Y & C \\
\hline A0500 & & 180 & MD & PY & 23 & YES & & Y & R \\
\hline
\end{tabular}

No. = numerical designation within Savannah river collection gr = gram staining $D_{M}=$ depth at which sample was taken (in meters)

$\mathrm{GF}=$ geological formation of origin $\mathrm{ME}=$ media, $\mathrm{T}=$ temperature of incubation in ${ }^{\circ} \mathrm{C}$

$\mathrm{Sp}=$ ability to form spores

$\mathrm{Si}=$ cell size (diamter)

$\mathrm{COL}=$ color of colony

$\mathrm{Sh}=$ cell shape

$\mathrm{EL}=$ Ellenton
$\mathrm{PD}=$ pee dee

$M D=$ middendorf

$\mathrm{PY}=\mathrm{PTYG}-\mathrm{AGAR}$

P1 = 1\% PTYG (peptone-tryptone-yeast extract-glucose) AGAR

$S=$ small, $L=$ large

$\mathrm{Y} / \mathrm{L}=$ yellow light

$Y=$ yellow

P.L = pink light

$\mathrm{C}=\mathrm{COCCI}$

$\mathrm{R}=\mathrm{rod}$ 
TABLE 3. Retention Data For The GF/D Filter Study With A0500: The Filters Were Whatman Binder-Free Glass

Microfiber Filters (Type GF/D): Borosilicate

Glass Fiber Fiters Nominal Pore Size $2.7 \mu \mathrm{m}$, Thickness $0.68 \mathrm{~mm}$

\begin{tabular}{|c|c|c|}
\hline $\mathbf{A}_{600}$ & $\begin{array}{c}\text { FRACTION BACTERIA RETAINED } \\
\text { IN THE FIITER }\end{array}$ & FLTTER NO. \\
\hline 1.317 & $3.2 \%$ & 1 \\
\hline 1.317 & $9.0 \%$ & 2 \\
\hline 1.317 & $14.0 \%$ & 3 \\
\hline
\end{tabular}

AVERAGE FRACTION OF BACTERIA RETAINED IN THE FILTERS

$\mathbf{A}_{600}$

1.317

$8.7 \%$ 


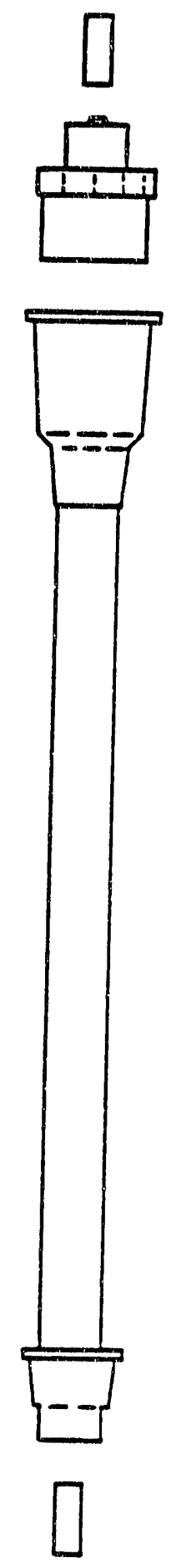

End caps - for stopping eluant flow or storing packed column.

Removable cap with Luerlock fittings- simplifies tubing connections.

Column reservoir- for manual sample application. Accepts accessory funnels and reservoirs.

Borosilicate glass barrel- clear, inert, durable.

Bed support- porvus (nominal $35 \mu \mathrm{m}$ ) polyethylene disc. Inert, retains small, soft particles without damage.

Column tip- standard Luerlock fitting with low dead volume.

Figure 1. Column apparatus for bacterial adhesion/stickiness screening experiemnts. 


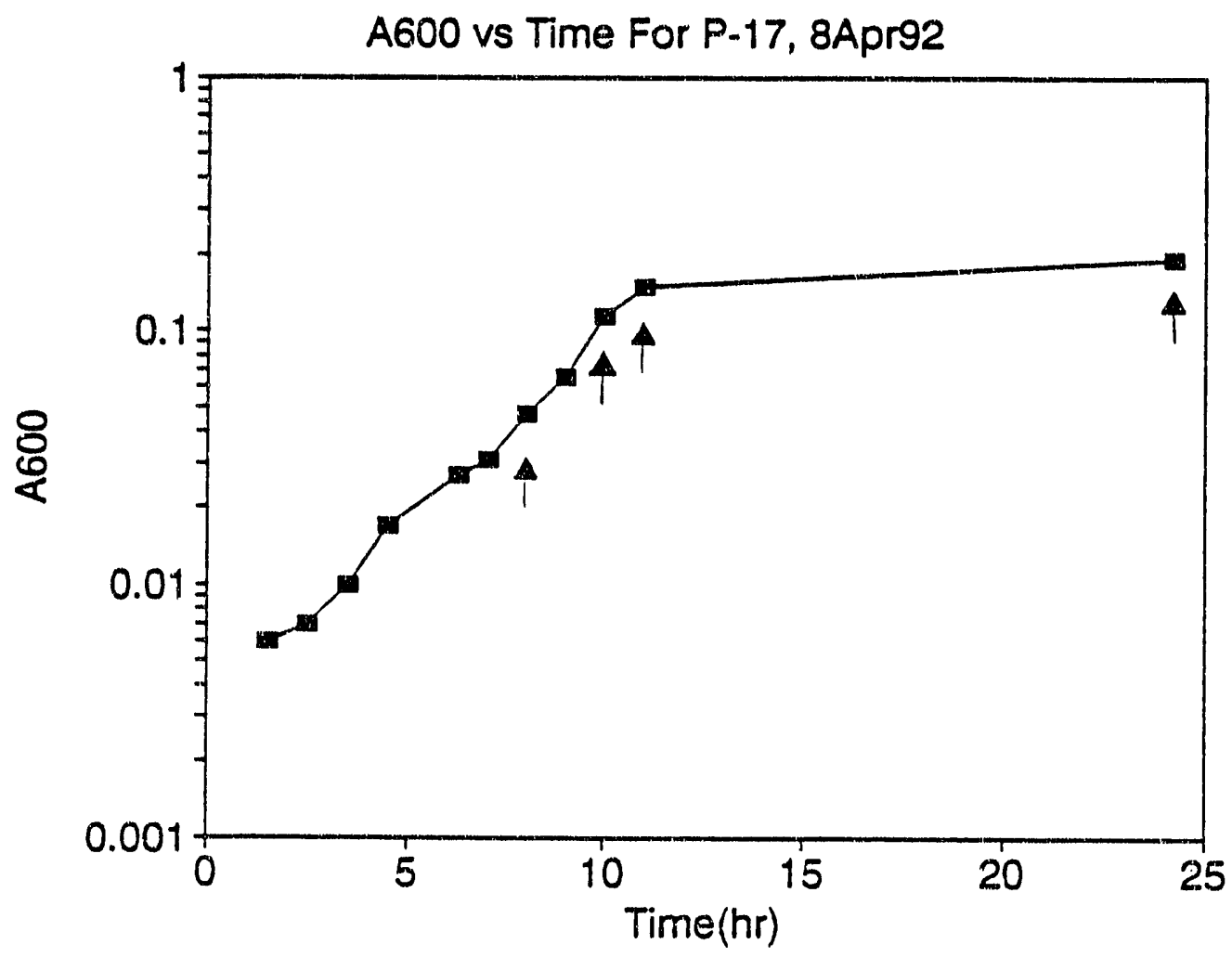

Figure 2. Optical density versus time in pure, batch cultures of P. fluorescens P17 grown in MOPS buffer/nutrients. Samples were withdrawn at the points indicated for measurement of cell retention via column and (commercial) filter procedures. $A_{600}=$ absorbance at $\lambda=600 \mathrm{~nm}\left(\mathrm{~cm}^{-1}\right)$. 


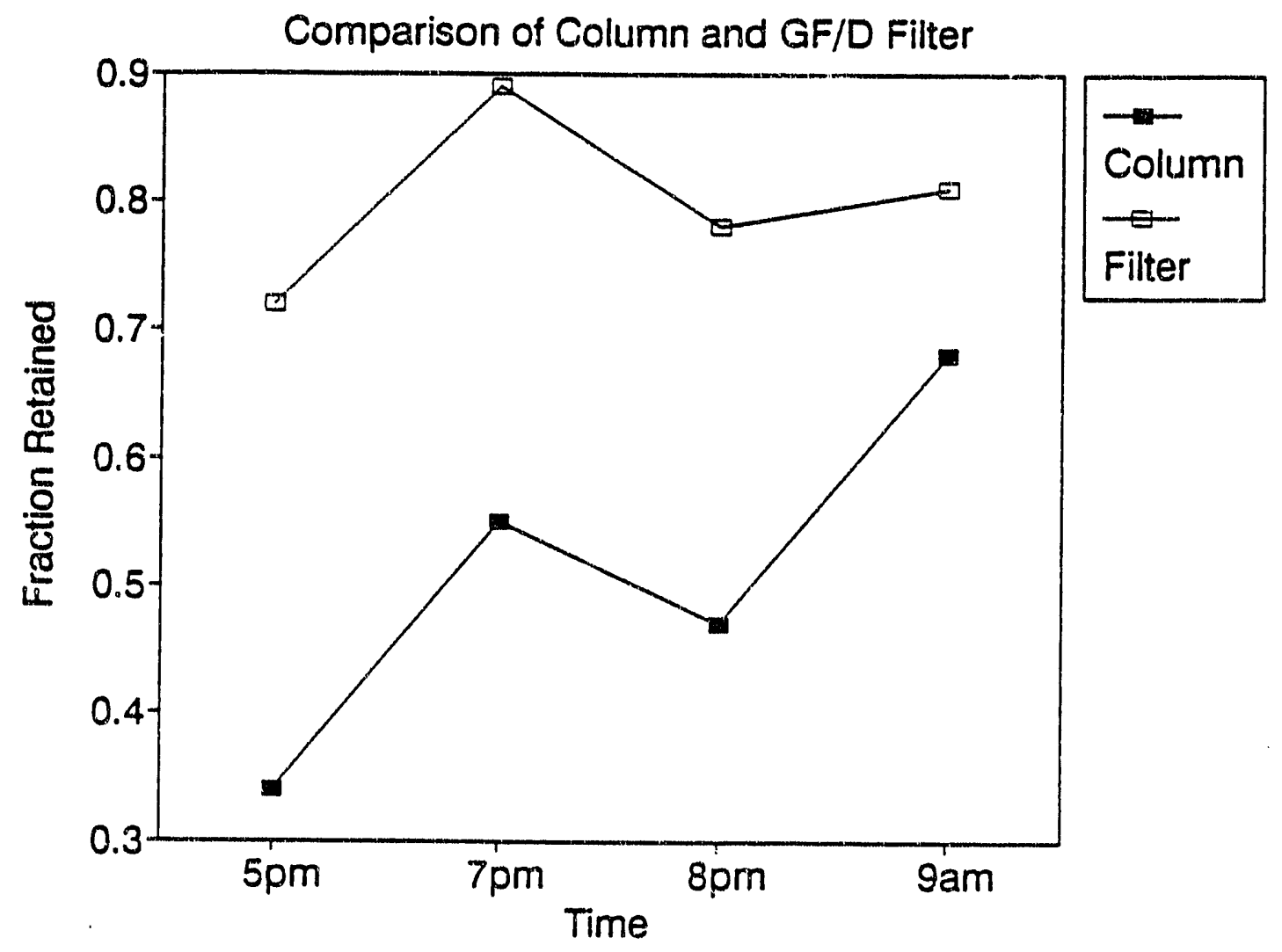

Figure 3. Comparison of column and (commercial) filter retentions using $\mathbf{P}$. fluorescens P17. Points correspond to those indicated on the (Figure 2) growth curve. Columns were filled to a depth of $9.0 \mathrm{~mm}$ with $40 \mu \mathrm{m}$ borosilicate glass beads. Column design features are summarized in Figure 1. Commercial filters were Whatman Binder-Free Glass Microfibre filters (GF/D): borasilicate glass fiber filters, nominal pore size $2.7 \mu \mathrm{m}$, thickness $0.68 \mathrm{~mm}$. 


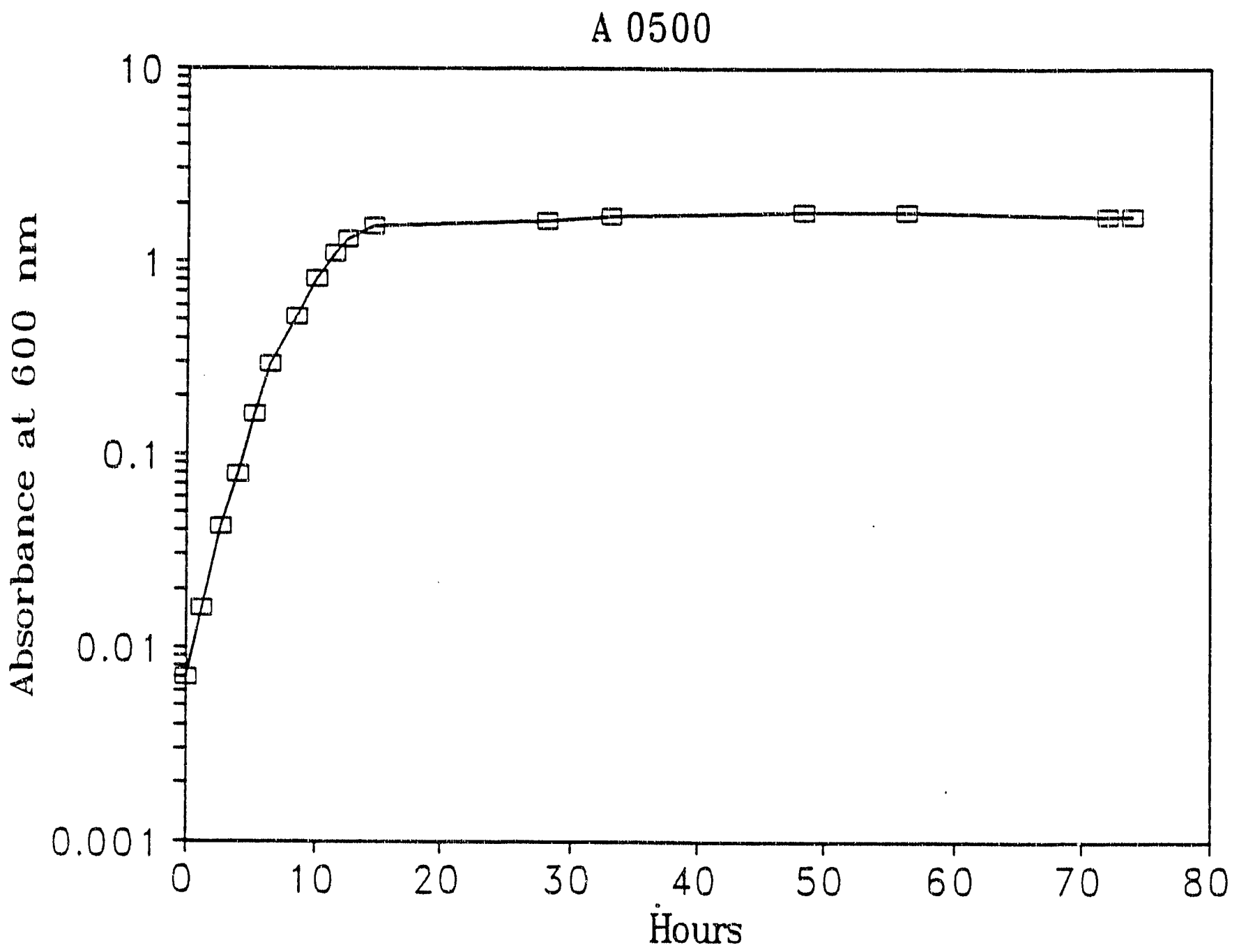

Figure 4a. Growth of Savannah River strain A0500 in PTYG medium. Samples were taken at the points indicated (3) for measurement of retention in the column/glass bead apparatus.

(doubling time $=2.8$ hours; specific growth rate $=0.25 \mathrm{~h}^{-1}$ ) 


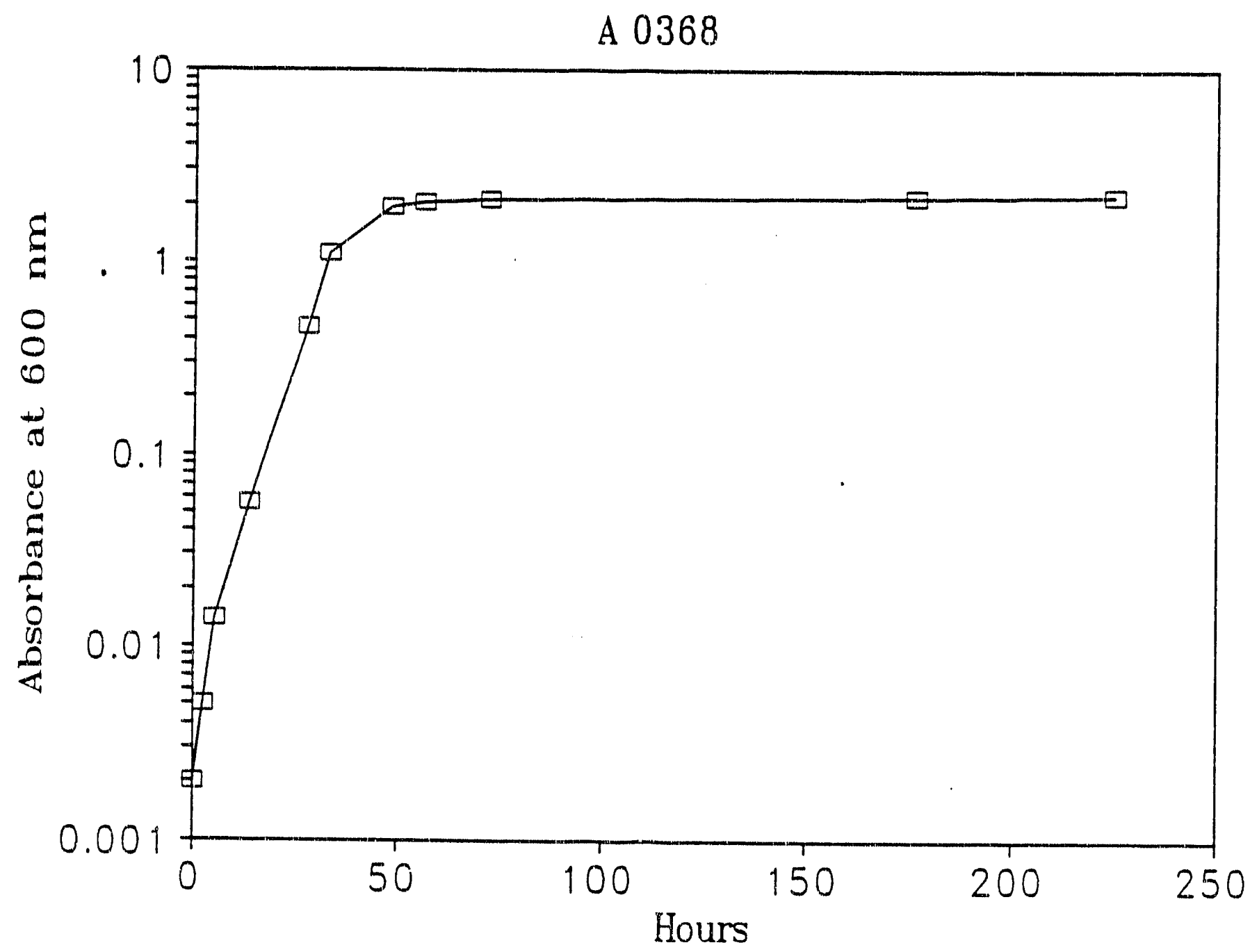

Figure 4b. Growth of Savannah River isolate A0368 in PTYG medium. (doubling time $=10.3 \mathrm{~b}$; specific growth rate $=0.67 \mathrm{~h}^{-1}$ ). 


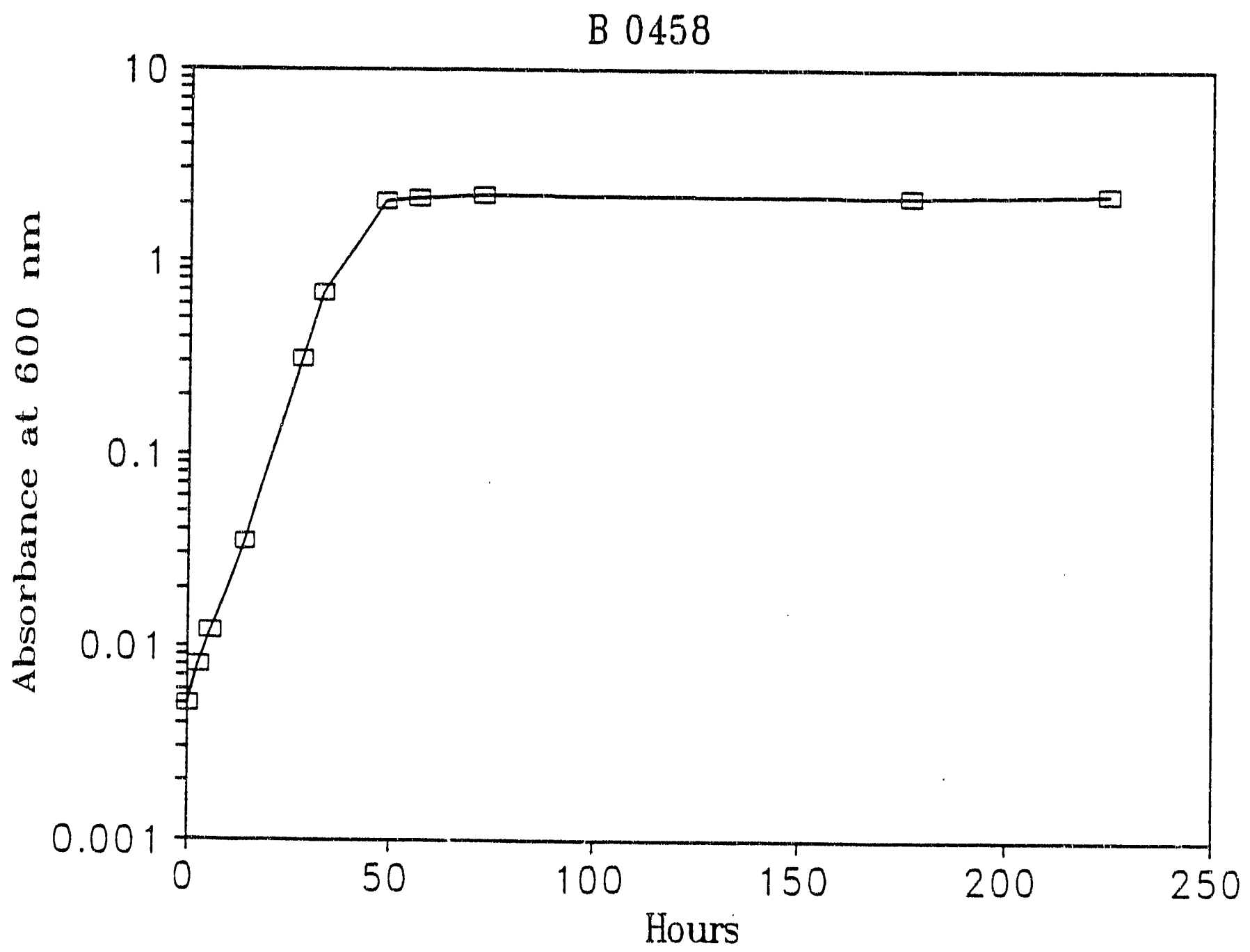

Figure 4c. Growth of Savannah River isolate AO368 in PTYG medium (doubling time $\left.=0.064 \mathrm{~h}^{-1}\right)$. 


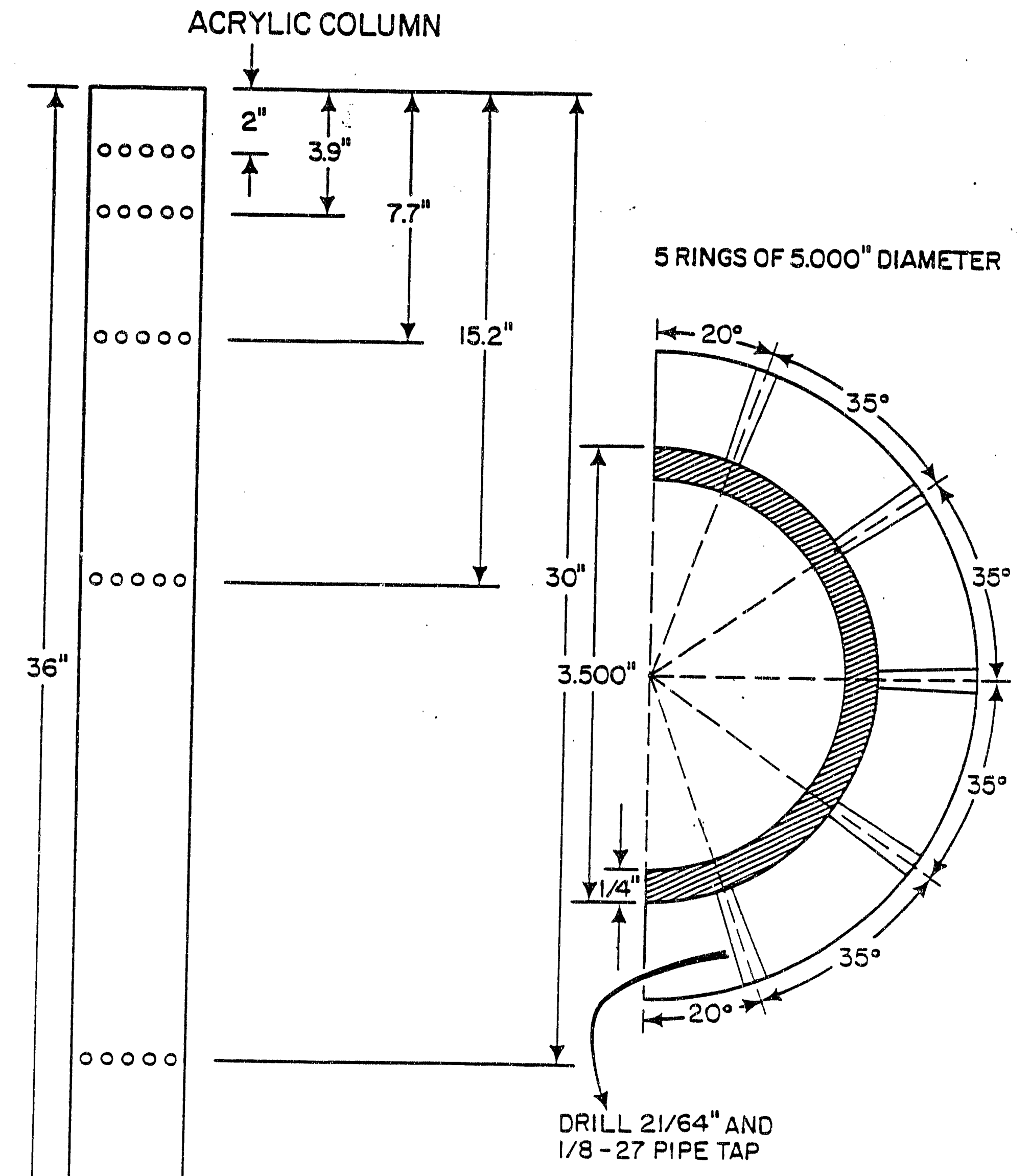

Figure 5. Design details for the 36-inch intermeidate scale, bacterial adhesion tests. 


\section{ACRYLIC COLUMN END CAP}

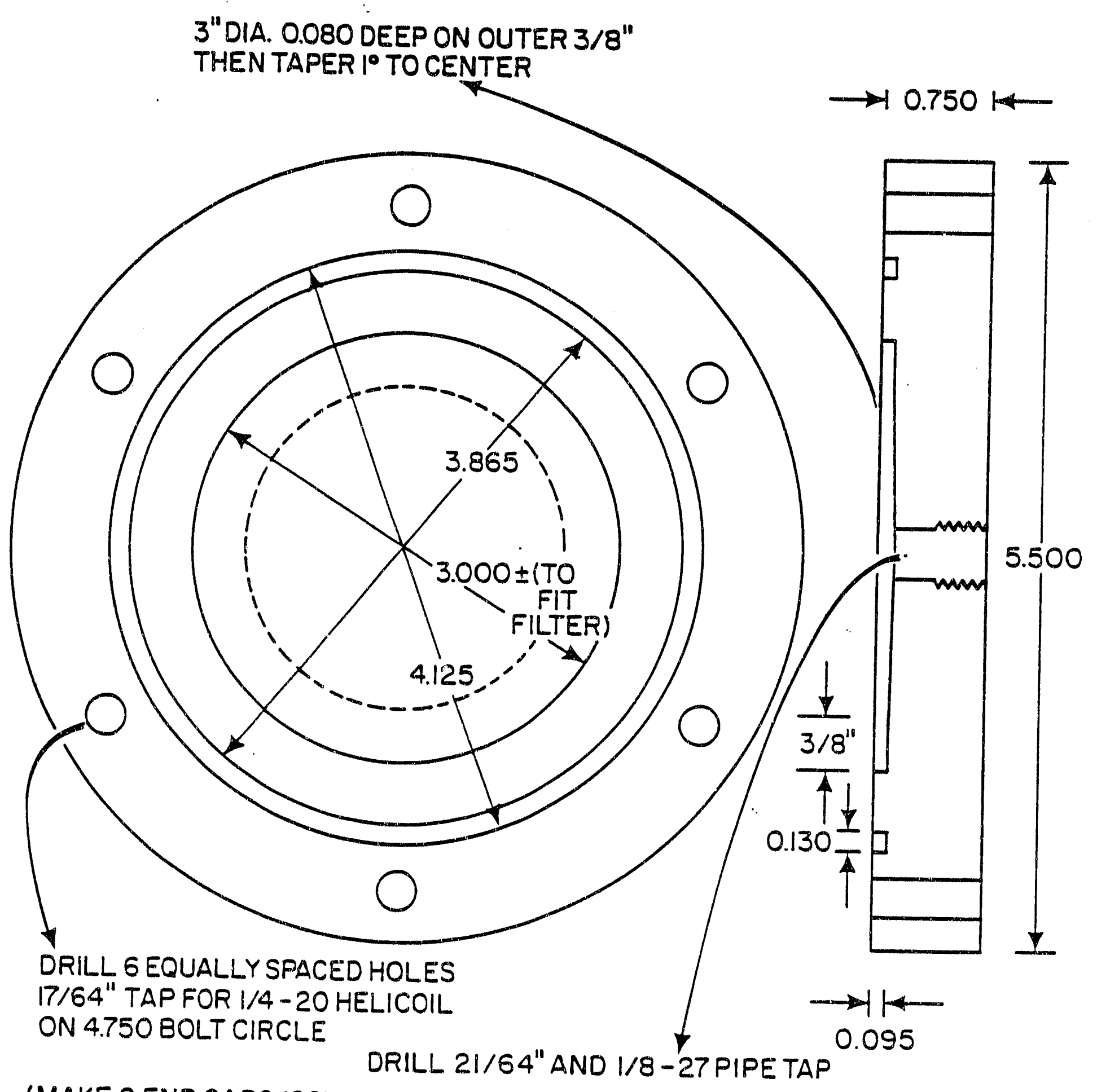

(MAKE 2 END CAPS/COLUMN.) 


\section{ACRYLIC COLUMN END FLANGE}

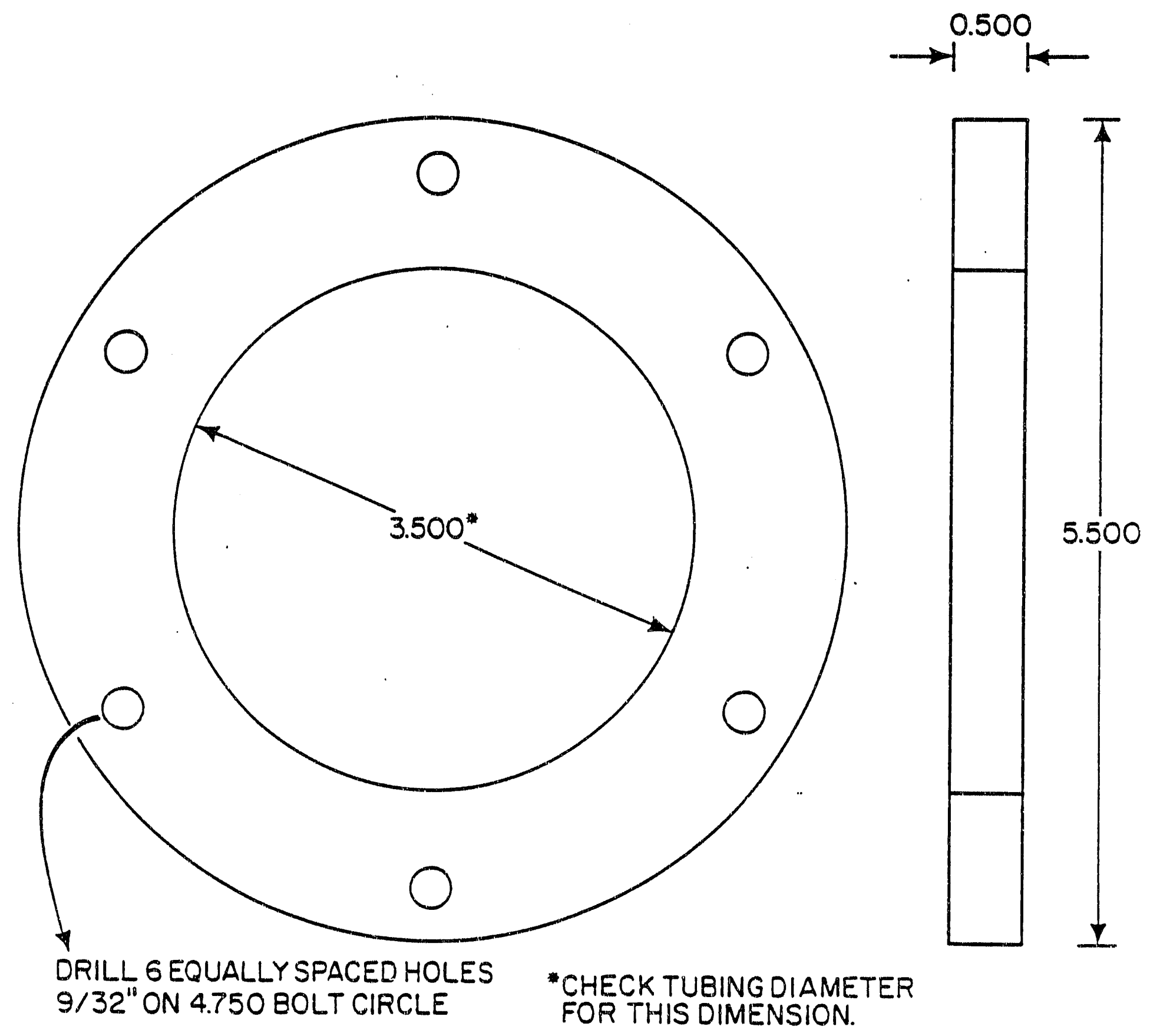

(MAKE 2 END FLANGES/COLUMN.)

ALL DIMENSIONS IN INCHES 

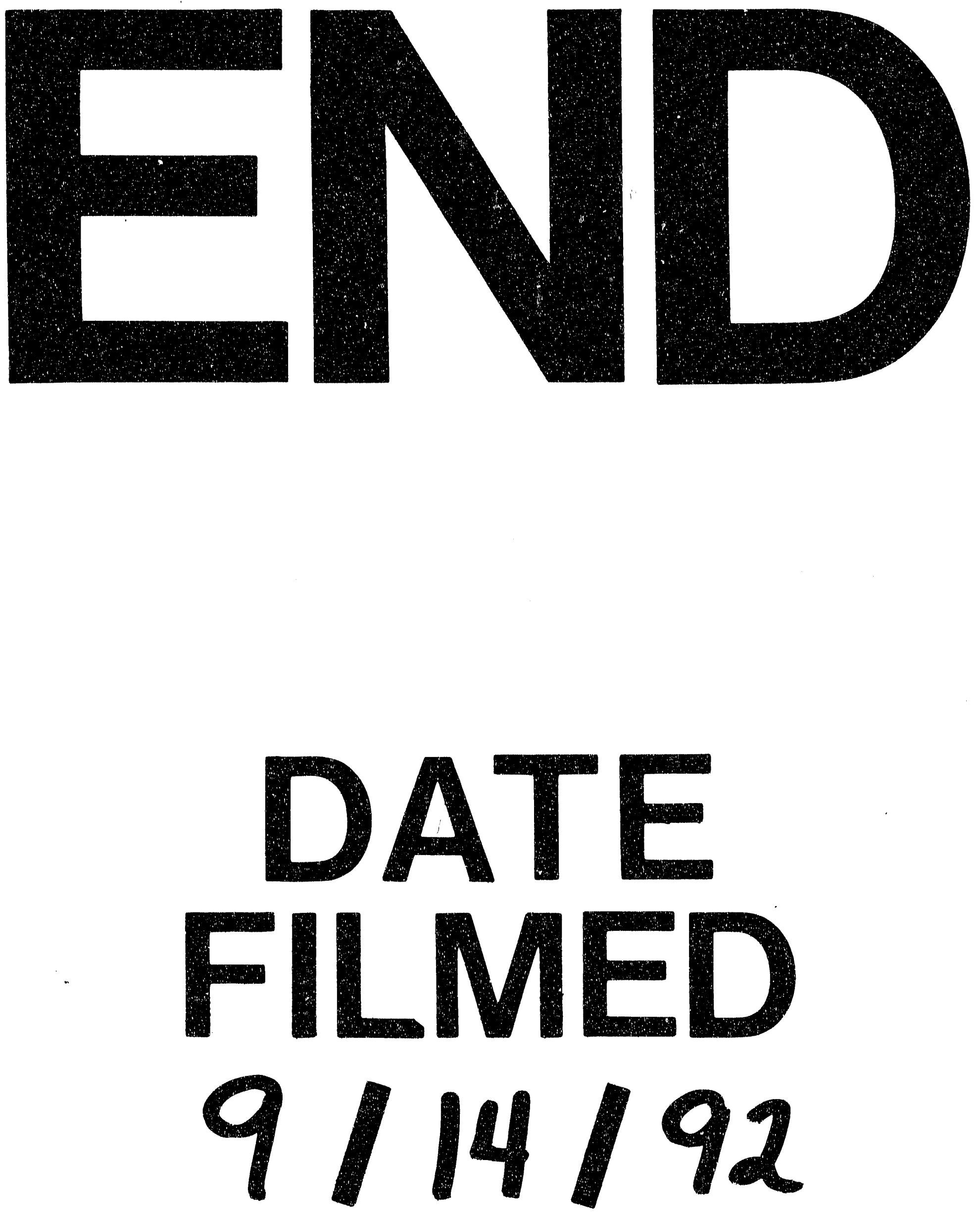